\title{
PORRESPONDENCE
}

\section{The Treatment of Gliomas in Adulthood}

by Prof. Dr. med. Roland Goldbrunner, Prof. Dr. med. Maximilian Ruge, Prof. Dr. med. Martin Kocher, Dr. med. Carolin Weiß Lucas, Prof. Dr. med. Norbert Galldiks, and PD Dr. med. Stefan Grau in issue 20-21/2018

\section{The Study Was Subject to Considerable Bias}

I am afraid I cannot let the section entitled "Tumortreating fields (TTF)" in the article stand uncommented (1).

The authors talk about valid study data and cite the study by Stupp et al. They mention the existing controversial discussion and name as the reason for this discussion the "visible stigmatization of patients that this form of treatment entails (the scalp must be cleanshaven, and electrodes must be fastened to the head for at least 18 hours per day)." The main point of criticism made of the study, which prompted the current controversial discussion, is not even mentioned as an aside - that is, the lack of a sham group (only the comparison of temozolomide and TTF + temozolomide.) Stupp et al. themselves pointed out this possible effect as one of the limitations of their study $(2,3)$; the reason they gave for the lack of a sham group is (understandable) ethical concerns $(2,3)$, and they claimed that the overall and progression-free survival (evaluated by a blinded panel) in cancer therapy is independent of any placebo effect (2). Stupp et al. support this claim by citing the study of Chvetzoff and Tannock $(2,4)$, which investigated placebo studies in cancer therapy (4); none of the studies included sham groups.

In Reply:

Dr. Haupt in his letter to the editor criticizes the study reported by Stupp et al., which was published in JAMA in 2017. His legitimate criticism is that the study included a deficient control group, in the sense that randomization had taken place, but true blinding had not. This means that placebo effects became relevant. This criticism is absolutely justified. Comprehensive discussions about "tumor-treating fields" (TTF) therapy has taken place in the neuro-oncological specialty societies; ultimately true blinding, as demanded by Haupt, is not possible in the setting of any treatment that the patient can feel. The limitation of a possible placebo effect therefore stands. In spite of this limitation, TTF therapy has moved up to the rank of "standard therapy" in Israel and the USA. This means that the relevant state agencies as well as the large insurance companies ended up being convinced by the effectiveness of the treatment. In my opinion, the
Furthermore, what is being ignored here is publication bias, which is certainly relevant in this setting, because studies with significant results are far more likely to be published-something that Chvetzoff and Tannock actually noted in their study (4).

In sum, I would ask the authors to mention this not inconsiderable bias, which probably affects the significance of the study or may even negate any significance.

DOI: 10.3238/arztebl.2018.0674a

\section{References}

1. Goldbrunner R, Ruge M, Kocher M, Weiß Lucas C, Galldiks N, Grau S The treatment of gliomas in adulthood. Dtsch Arztebl Int 2018; 115: 356-64.

2. Stupp R, Taillibert S, Kanner AA, et al:: Maintenance therapy with tumor-treating fields plus temozolomide vs temozolomide alone for glioblastoma: a randomized clinical trial. JAMA. 2015; 314: 2535-43.

3. Stupp R, Taillibert S, Kanner A, et al.: Effect of tumor-treating fields plus maintenance temozolomide vs maintenance temozolomide alone on survival in patients with glioblastoma: a randomized clinical trial. JAMA 2017; 318: 2306-16.

4. Chvetzoff G, Tannock IF: Placebo effects in oncology. J Natl Cancer Inst 2003; 95: 19-29.

\section{Dr. med. Malte Haupt}

Klinikum Herford

malte1487haupt@yahoo.de

\section{Conflict of interest statement}

The author declares that no conflict of interest exists. cautious but positive description in our article was therefore justified.

DOI: 10.3238/arztebl.2018.0674b

\section{References}

1. Stupp R, Taillibert S, Kanner A, et al.: Effect of tumor-treating fields plus maintenance temozolomide vs maintenance temozolomide alone on survival in patients with glioblastoma: a randomized clinical trial. JAMA 2017; 318: 2306-16.

2. Goldbrunner R, Ruge M, Kocher M, Weiß Lucas C, Galldiks N, Grau S: The treatment of gliomas in adulthood. Dtsch Arztebl Int 2018; 115: 356-64.

On behalf of the authors

Prof. Dr. med. Roland Goldbrunner

Klinik für Allgemeine Neurochirurgie

Zentrum für Neurochirurgie

Universitätsklinikum Köln

roland.goldbrunner@uk-koeln.de

\section{Conflict of interest statement}

Prof. Goldbrunner has served as a paid consultant for MagForce and has received reimbursement of meeting participation fees and of travel and accommodation expenses from Roche. 